\title{
O ENSAIO COMO PROCEDIMENTO DE LEITURA-ESCRITURA EM “O ESPÍRITO DOS MEUS PAIS CONTINUA A SUBIR NA CHUVA"
}

\author{
Rafael Gurgel Almeida ${ }^{1}$ \\ Mônica de Menezes Santos ${ }^{2}$
}

\begin{abstract}
Resumo: Neste trabalho, ler-se o romance $O$ espírito dos meus pais continua a subir na chuva, de Patricio Pron, de modo a investigar como o autor se apropria da memória a respeito da última ditadura militar argentina, ingressando no que tem sido chamada de "literatura dos filhos" (COSTA; SANTOS, 2016). Para tanto, aciona-se material teórico que problematiza a recuperação historiográfica e a diluição das fronteiras entre real e ficção. Aqui, o Ensaio enquanto forma e postura investigativa torna-se o procedimento balizador, sobretudo por dizer de uma aproximação que acolhe a incerteza a respeito de seu objeto.
\end{abstract}

Palavras-Chave: Ditadura militar. Argentina. Literatura contemporânea. Patricio Pron. Ensaio.

\section{THE ESSAY AS A READING-WRITING PROCEDURE IN "THE SPIRIT OF MY PARENTS CONTINUES TO RISE IN THE RAIN"}

\begin{abstract}
In this paper, we read the novel The spirit of my parents continues to rise in the rain, by Patricio Pron, investigating how he appropriates an collective memory regarding the last argentine military dictatorship - entering what has been called "children's literature" (COSTA; SANTOS, 2016). For that, we used material that problematizes the historiographic recovery and the dilution of boundaries between real and fiction. The Essay becomes the guiding procedure, especially for its approach that welcomes the doubt.
\end{abstract}

Keywords: Military dictatorship. Argentina. Contemporary literature. Patricio Pron. Essay.

O narrador de $O$ espírito dos meus pais continua a subir na chuva, romance do escritor argentino Patricio Pron, inicia o texto contando que lembra pouca coisa dos oito anos em que viveu na Alemanha. As drogas

1 Mestrando em Literatura e Cultura pelo PPGLitCult (UFBA).E-mail: mrgurgel95@gmail.com.

2 Professora de Literatura Brasileira do Programa de Literatura e Cultura da UFBA (PPGLitCult). E-mail: momesa@ufba.br. 
(receitadas por um psiquiatra) fez com que guardasse imagens imprecisas e aparentemente desconexas, como a porta do consultório, os quartos em que viveu e a neve entrando nos sapatos: "Entre março ou abril de 2000 e agosto de 2008, oito anos em que viajei e escrevi artigos e morei na Alemanha, o consumo de certas drogas fez com que eu perdesse quase completamente a memória" (PRON, 2018, p. 9). Num dia de agosto de 2008, telefona à família na Argentina e descobre que o pai está desacordado num hospital. Em decorrência da notícia, retorna ao seu país de origem e percebe subir-lhe à consciência algumas lembranças de não-pertencimento (anteriores à década em que esteve longe).

De volta à casa dos pais, o narrador-personagem contempla a estante de livros e vê não aquilo que eles leram, mas o que lhes faltou: "Autores ausentes na biblioteca dos meus pais: Bullrich, Silvina; Guido, Beatriz; Martínez Estrada, Ezequiel; Ocampo, Victoria; Sabato, Ernesto." No entanto, o movimento é também de, pouco a pouco, recuperar os ideais de uma geração: "Palavras que provavelmente mais aparecem nos livros da biblioteca dos meus pais: tática, estratégia, luta, Argentina, Perón, revolução" (PRON, 2018, p. 28). Percorrendo esses rastros, chega ao escritório do pai e encontra uma pasta contendo vários recortes de jornais (recentes e não tão recentes) sobre pessoas desaparecidas. Assim descobre que, em seus últimos dias acordado, o pai esteve obcecado pelo desaparecimento de um homem até então desconhecido ao narrador: Alberto Burdisso.

Para Marcos Tolentino, o retorno à democracia após a última ditadura militar argentina (iniciada em 1976) colocou a figura do desaparecido numa posição de centralidade nos debates sobre memória e justiça - debates que a recuperaram "através de uma multiplicidade de discursos, práticas e estratégias" (TOLENTINO, 2012, p. 51). Nesse sentido, quando Pron aciona o desaparecido, ainda que narrativamente situado em 2008, nos parece mobilizar uma série de aparatos simbólicos capazes de provocar em quem lê a lembrança de um tempo e as disputas que o sucederam, principalmente porque os ataques aos direitos humanos cometidos pelas forças oficiais formaram parte significativa da opinião pública: 
A partir de 1995 abriu-se um novo período, através da confissão televisiva do oficial aposentado do exército, Adolfo Scilingo, sobre sua participação nos "voos da morte" - o que contribuiu para que a questão novamente adquirisse centralidade na opinião pública. Somaram-se posteriormente outros acontecimentos relevantes, como a autocrítica do então comandante do exército, o começo dos julgamentos pela verdade e pelo sequestro de crianças durante a ditadura militar, o nascimento do grupo H.I.J.O.S., a nulidade das leis de Obediência Devida e Ponto Final, a proliferação de monumentos, filmes, documentários e livros, a crescente magnitude dos atos de comemoração ao 24 de março, entre outros. Tudo isso configurou um "boom da memória" na medida em que o passado ditatorial ocupou um lugar sempre de destaque na cena pública (LVOVICH; BISQUERT, 2008, p. 13. Tradução nossa).3

A transição do regime ditatorial para a democracia provocou, tanto nas produções artísticas quanto na crítica, a preocupação com a restituição de humanidade às vítimas. Para Cynthia E. Milton, a arte produzida a partir de um passado fraturado tornou-se não apenas o lugar do testemunho, mas também da transmissão de memória, possibilitando que quem não viveu diretamente tais acontecimentos se apropriasse e os reconhecesse com maior empatia (MILTON, 2018, p. 19) - um espelho do que ocorre no romance de Pron.

Após uma primeira parte narrando o reencontro com a família, as lembranças de sua infância que emergiam a partir desse reencontro e a descoberta de documentos guardados pelo pai, na segunda parte do livro o narrador percebe uma simetria entre as histórias contidas na pasta: Alicia, a irmã de Alberto, desapareceu após sequestro pelas forças oficiais em 1977. Seu corpo jamais foi encontrado. O do irmão, por outro lado, desapareceu em 2008

\footnotetext{
${ }_{3}$ A partir de 1995 se abrió un nuevo período, a partir de la confesión televisiva del oficial retirado de la armada, Adolfo Scilingo, sobre su participación en los "vuelos de la muerte", que contribuyó a que la cuestión adquiriera nuevamente centralidad para la opinión pública. Se le sumaron posteriormente otros acontecimentos relevantes, como la autocrítica del entonces comandante en jefe del ejército, el comienzo de los juicios por la verdad y de los juicios por apropiación de niños durante la dictadura militar, el nacimiento de la agrupación H.I.J.O.S., la nulidad de las leyes de Obediencia Debida y Punto Final, la proliferación de monumentos, películas, documentales y libros, la creciente magnitud de los actos de conmemoración del 24 de marzo, entre otros. Todo esto configuró um "boom de la memoria" en la medida en que el pasado dictatorial ocupó un lugar siempre destacado en la escena pública.
} 
e permaneceu por vinte dias num poço até exalar o forte mau cheiro que chamou atenção de um caçador.

Alicia desapareceu numa guerra política; Alberto por conta de uma casa que "lembra uma cadeira de encosto alto jogada de cabeça para baixo em um terreno baldio, em um terreno onde ninguém jamais ia querer morar" (PRON, 2018, p. 85), comprada com parte da indenização recebida pelo ocorrido à irmã. Segundo uma das matérias a que tem acesso o narrador, "uma trapaceira queria ficar com sua propriedade e para isso convenceu outros dois homens e outras pessoas da necessidade de sumirem com ele, para nunca mais ser encontrado" (ibidem, p. 83). No mise en abyme de mortes, aparece uma guerra suja:

A guerra suja foi a zona de atrocidade - torturas, desaparições misteriosas, corpos destroçados, massacres - , na qual não se respeitaram as regras legais normais, os tabus culturais, nem as regras da própria guerra. Também foi a zona em que os Estados podiam esconder a verdade de seus feitos, negando seu conhecimento ou inventando embustes. A guerra suja concedeu ao Estado o suposto direito de violar aquele que se interpusesse no caminho, que pudesse servir como um assustador exemplo instrutivo aos demais, ou que tivesse servido como instrumento de cumplicidade ou inteligência (STERN, 2018, p. 293-294. - Tradução nossa). 4

Marcos Tolentino também aponta que "as pessoas desapareciam em procedimentos espetaculares, muitas vezes na via pública, e com a presença de testemunhas", levadas a circuitos de detenção localizados em zonas urbanas densamente povoadas (TOLENTINO, 2012, p. 39). A guerra suja acontecia à vista de civis, mas era envolta por um manto de silêncio e medo que permitia à maioria das pessoas não implicar-se no conflito. Esse olhar

\footnotetext{
${ }^{4}$ La guerra sucia fue la zona de atrocidad - torturas, desapariciones misteriosas, cuerpos trozados, masacres - , en la que no se respetaron ni las reglas legales normales ni los tabúes culturales, ni siquiera las reglas de la guerra. También fue la zona en la que los Estados podían impugnar la verdad de los hechos negando su conocimiento o inventando tapaderas. La guerra sucia concedió al Estado el supuesto derecho de violar al que se interpusiera en el camino, al que pudiese servir como un aterrador ejemplo instructivo para los demás o al que hubiese servido de instrumento de complicidad o inteligencia.
} 
invisível é esboçado pelo narrador de Pron quando conta que em El Trébol, sua cidade natal,

não havia nada para fazer além de espiar e ser espiado e manter uma aparência de responsabilidade e seriedade que até as crianças eram obrigadas a simular, com a visita semanal e obrigatória à igreja e o respeito às celebrações nacionais e, de maneira geral, com o cultivo constante da hipocrisia e das aparências, que pareciam ser parte de uma tradição local da qual os habitantes de El Trébol eram particularmente orgulhosos e tinham decidido tacitamente defender contra os embates da verdade e do progresso, que nessa cidade eram considerados estrangeiros (PRON, 2018, p. 50).

Patricio Pron, portanto, implica a cidade nas duas mortes, traz à superfície o silêncio, os olhos que espiam por detrás das cortinas e as pessoas que se sentam à porta. Essas são entradas possíveis para investigar como o texto desestabiliza as fronteiras entre real e ficção, mobilizando inclusive uma responsabilidade coletiva. A dobra no tempo - ou seja, a sobreposição entre uma morte em 1977 e outra em 2008 -, parece-nos não apenas produzir memória sobre a ditadura como questionar em que medida os cochichos hipócritas contribuem para a continuidade da violência.

Esse hibridismo nas fronteiras entre mídias, artes e formas de discurso não é algo novo para os estudos literários. Florencia Garramuño propõe que a inespecificidade lança a literatura para uma zona em que vale mais pelo que diz de conflitos sociais e existenciais habitando um espaço fora do livro (GARRAMUÑO, 2014). Textos são continuamente enxertados de sentido em feiras, bienais, tuítes, resenhas no instagram e outras modalidades discursivas que permitem a autor (e leitores) confrontá-los com o real; a demanda por representatividade, por exemplo, parece-nos bastante imbricada com esse movimento. Não trata-se apenas de interpretar ou conjecturar sobre um fechamento para passagens em aberto, mas de apropriar-se do livro e usálo como ferramenta pedagógica, produzindo rasgos no tecido e recolhendo os retalhos que sirvam para outra costura. Desse modo, as palavras estão "além de quem escreve, e também além de quem lê, mas também além da própria 
literatura, no mundo, como as palavras de uma carta que pode ou não chegar a seu destino" (VIDAL, 2014, p. 121, tradução nossa). ${ }^{5}$

No epílogo de $O$ espírito dos meus pais, Pron conta que embora "os fatos narrados neste livro sejam essencialmente verdadeiros, alguns deles são produto das necessidades do texto ficcional" (PRON, 2018, p. 158) - e, neste sentido, não conseguimos deixar de nos perguntar quais seriam essas necessidades, o que especificamente a ficção solicita que um ensaio, artigo, memória, diário ou texto jornalístico não o faça. Por acaso textos que "relatem" acontecimentos observáveis também não acionam estratégias "romanescas"? Para Hayden White, em Trópicos do discurso, "[toda] história precisa submeter-se tanto a padrões de coerência quanto a padrões de correspondência se quiser ser um relato plausível do "modo como as coisas realmente aconteceram":

[...] uma simples lista de afirmações existenciais singulares, passíveis de confirmação, não indica um relato da realidade se não houver alguma coerência, lógica, ou estética que as ligue entre si. Da mesma forma, toda ficção deve passar por um teste de correspondência (deve ser "adequada" como imagem de alguma coisa que está além de si mesma), se pretender apresentar uma visão ou iluminação da experiência humana do mundo (WHITE, 1994, p. 138).

Algumas considerações de White na obra citada são bastante polêmicas, mas chamam atenção para algo de especial importância a quem se interessa pelo trabalho com a palavra: não há como concatenar episódios, ainda que reais, sem pensar no estabelecimento de sentidos, numa lógica ordenadora, justamente porque não há fato que fale por si, sem mediação. $O$ historiador, o romancista, o poeta, o biógrafo, aquele que escreve diários e memórias, todos estão manejando com o real a partir da representação.

O historiador francês Ivan Jablonka (2017, p. 10), ao desenhar o que chama de mapa-mundi da escrita, alarga tal discussão. No mapa, Jablonka identifica dois continentes: em um são encontrados os "territórios da

${ }^{5}$ [...] más allá de quien escribe y también más allá de quien lo lee, pero también más allá de la literatura misma, en el mundo, como las palabras de una carta que puede o no llegar a su destino. 
liberdade e do imaginário", ou seja, a literatura; no outro, "os terrenos áridos do real e do verídico": os artigos de imprensa, os documentos, as notícias, os discursos etc - os textos utilitários. No exterior de tal cartografia, no entanto, há textos e autores que não se enquadram. E é nessa zona cinzenta em que figuram as ficções da realidade:

Textos mais desejosos de compreender do que de narrar ou inventar; uma forma de escrita alimentada pelo espírito das ciências sociais, atormentada pela vontade de decifrar o nosso mundo; uma literatura que procura compreender o que está acontecendo, o que se passa, o que se passou, o que os desaparecidos e o mundo antigo se tornaram; um novo espaço que permite inscrever o verdadeiro em formas renovadas (p. 17).

Há trabalhos poéticos e ficcionais que acionam abordagem e método na mesma medida em que incursões históricas estariam mobilizando procedimentos "da ficção" (JABLONKA, 2017). Ou seja, a escrita de um romance certamente pode prescindir - mas não necessariamente prescinde de uma pergunta norteadora, da incursão em arquivos, das entrevistas com testemunhas e de outras tantas necessidades do texto "histórico". Essa divisão, portanto, é muito mais social do que necessariamente revela alguma essência dos textos.

Ficção não significa o mesmo que reivindicação do falso. Ela tanto não nega a existência de uma realidade objetiva, como também não está plasmada na farsa absoluta. É um modo específico de ver o mundo, de abordar a realidade. Quando Pron, em seu posfácio, revela que não inventou nenhum acontecimento, está nos dizendo que seus personagens contam com referentes verificáveis. À vista disso, lançar mão das "necessidades da ficção" talvez signifique, abrindo mão das pretensões do absoluto, especular; ou seja, operar a partir da possibilidade - o que não deixa de ser produção de pensamento. "O paradoxo típico da ficção reside em que, se recorre ao falso, o faz para aumentar sua credibilidade” (SAER, 2012, p. 3).

O romance de Pron é como uma supernova expulsando matéria para o espaço, uma estrela que, de seu estado original, passa a provocar uma constelação de sentidos. Se o lemos como livro de memórias, esbarramos no 
esforço poético de encenação do fracasso, sobretudo através dos grumos narrativos, das pequenas ilhas textuais a pouco distender-se sobre pessoas e acontecimentos (não há descrições pormenorizadas de cena alguma, senão um exercício crítico, de escrutínio mental e ensaístico, à procura por um sentido, por algo que organize os eventos). Se o lemos estritamente como ficção, damos de encontro com pessoas e eventos que contam com referentes verificáveis. Tal organização, apesar de executada através de uma aparente desordem (expressa em não-linearidade), é justamente a estética, a lógica e a coerência a ligar os acontecimentos. Os sentidos que o narrador produz espraiam-se, solicitando do leitor uma leitura outra, uma leitura que o coloque na posição ativa de quem aciona os próprios conhecimentos históricos. O espírito dos meus pais continua a subir na chuva, ao expor a precariedade do próprio conhecimento, incide politicamente sobre o real - e, desse modo, voltamos às proposições de Garramuño: não há apenas encenação autobiográfica, mas interesse em produzir um livro que não se encerre na própria encadernação. Ao produzir-se enquanto se expõe, ao fazer um texto que pondera sobre os episódios mais do que os conta, Pron acena para o Ensaio enquanto forma.

Essai, conhecido em francês desde o século XII, provem do baixo latim exagium, a balança; ensaiar deriva de exagiare, que significa pesar. Nas proximidades desse termo se encontra examen: agulha, lingueta do fiel da balança, e, por extensão, exame ponderado, controle. Mas um outro sentido de "exame" designa o enxame de abelhas, a revoada de pássaros. A etimologia comum seria o verbo exigo, forçar para fora, expulsar, e daí exigir. Quantas tentações, se o sentido nuclear das palavras atuais devesse resultar do que elas significaram num passado longínquo! O ensaio seria a pesagem exigente, o exame atento, mas também o enxame verbal cujo impulso se libera (STAROBINSKI, 2011, p. 13).

O narrador de $O$ espírito dos meus pais continua a subir na chuva lança fora seus medos, concatena as cenas que gradativamente lhe voltam à memória e pondera sobre os afetos de uma geração anterior à sua, examinando o que lia, como criou os filhos e como lidou com o golpe militar de 
76. O gesto não é autoindulgente, girando em torno de si, mas justamente de produzir pensamento interessado pelo que aconteceu à sociedade (mesmo que a partir da própria experiência).

Alberto Burdisso não foi assassinado em virtude dos acontecimentos que tiraram a vida de sua irmã, mas sua morte pode revelar uma violência - ou um poder desaparecedor - que continua se processando ainda que não necessariamente a partir do Estado. É quase como se o corpo abandonado num poço, respirando por debaixo de escombros, esboçasse uma estética do desaparecimento, uma banalização da eliminação do outro. É impossível referir-se ao desaparecimento de Burdisso sem lembrar de sua irmã - e, ao fazê-lo, abre-se uma ferida histórica: privado e público se encontram.

Através do mergulho nos próprios arquivos, o narrador de Pron ensaia, tateia, faz aproximações preliminares, mas a partir da tentativa de escrever um romance, lançando mão das "necessidades da ficção". Seu trabalho é de escrutínio investigativo, mas há também a tentativa de contar uma história sem forma, que não pode ser como um romance policial - afinal, o primeiro crime (a morte de Alicia) não tem resolução. Os personagens não farão grande coisa além de esconder-se em silêncio, os cenários não terão, conforme já exposto, descrições minuciosas, e as cenas não serão mais do que sopros, balbucios de memória como uma fumaça muito fina: espíritos que sobem na chuva.

Pron tem um procedimento, uma história a contar, mas essa história acontece sobretudo quando levanta a cabeça. Ele sabe que fala de um lugar e por isso não tem certezas a oferecer, não pode ocupar o posto de narrador autoritário, onisciente, que a tudo dispende uma construção ostensiva - sua fala é entrecortada por soluços e pausas.

Como seria o romance que meu pai gostaria de escrever? Breve, feito de fragmentos, com lacunas onde meu pai não quisesse ou não conseguisse se lembrar de algo, feito de simetrias - histórias duplicando-se a si mesmas incessantemente, como uma mancha de tinta em um papel dobrado incontáveis vezes, um tema simples repetido continuamente como numa sinfonia ou no 
monólogo de um idiota - e mais triste que o dia dos pais em um orfanato (PRON, 2018, p. 108).

Para "satisfazer plenamente à lei do ensaio é preciso que o ensaiador se ensaie a si mesmo" (STAROBINSKI, 2011, p. 19). Pron - ou a encenação de si no romance - traz a crise para a superfície e mostra a impossibilidade de falar se não for marcado pelo seu lugar de filho, de quem herda uma derrota - ou de quem a viveu lateralmente, através da experiência protegida da infância. Ele sabia apenas que devia andar em direção contrária ao trânsito, mas não entendia por qual motivo: "Quando andava sozinho pela rua, tinha que caminhar em direção contrária ao trânsito e prestar atenção se algum carro parasse perto de mim" (PRON, 2018, p. 130). Se fala dos anos 70, é através de reminiscências, de rastros com uma curiosidade imensa de saber o que se passava, mas que não passam de cenas pouco nítidas.

Diante disso, compreendemos que o Ensaio é não apenas procedimento, mas também enxerto que permite elucubrar sobre tais imagens espectrais. A partir da explosão de sentidos, O espírito dos meus pais continua a subir na chuva gira em torno do "como se, imaginemos e suponhamos: na concepção de uma pura possibilidade" (LUDMER, 2014, p. 8). O que podem os filhos se não especular? Sua memória é disparada pelo que o presente mobiliza, não há como voltar à consciência da infância.

É importante que esses jovens possam marcar sua posição e encontrar uma voz própria. Porque essa história, e a inevitabilidade de participar de algo tão avassalador, ainda necessita que a contem a partir dessas outras perspectivas, que procurem atualizar seus efeitos e reestabelecer a importância de manter viva a memória (COSTA; SANTOS, 2016, p. 362, tradução nossa).6

Pron não foi torturado, não é filho de desaparecidos, não carrega o trauma do corpo empurrado ao limite da dor. O discurso que sua geração pode assumir é justo o de "lembrar para que não se repita". Seu romance é este

\footnotetext{
6 Es importante que estos jóvenes puedan marcar su posición y encontrar una voz propria. Pues esa historia, y la inevitabilidad de participar de algo tan avassalador, aún necessita que la cuenten a partir de estas otras perspectivas, que logren actualizar sus efectos y restablecer la importancia de mantener viva la memoria.
} 
porque a literatura parece cada vez mais assaltada por um constrangimento do real: que verdade pode encenar quem não viveu?, qual sua capacidade de criar um "romance com R maiúsculo", de descrições ostensivas que praticamente produzam uma pintura diante do leitor? Logo, sua estética é também uma ética: o narrador assume que fala de um lugar e torna a precariedade disparadora da escritura - talvez no que Reinaldo Laddaga (2013) chamaria de a patética comédia do escritor que se apresenta semimascarado.

[O] escritor que é consciente de sua ignorância e de sua insuficiência, o escritor a esta altura da história, não devia se apresentar como o agente que percebe tudo, que conhece tudo, que pode tudo, o artífice e o diretor que domina os romances de Jane Austen. O escritor tem que escrever de tal modo que o leitor possa recuperar em seus textos os sinais das ações que alguém teve de exercer para que se deslumbrassem as tentativas e manobras de um agente parcialmente ignorante, fatalmente limitado. Por quê? Porque não fazê-lo seria desonesto (LADDAGA, 2013, p. 48).

Em tal direção, as operações do Ensaio nos parecem reclamar: (1) autoconsciência, ou seja, atenção voltada para os próprios artifícios da investigação; (2) investimento nas considerações íntimas, de conhecimento "leigo", no pensamento que reservamos às elucubrações privadas; (3) profunda curiosidade pelo que ocorre fora de si, ainda que produzindo reflexão a partir do próprio lugar, das próprias experiências, daquilo que o olho e o tato conseguem alcançar.

Seria desonesto não se apresentar como agente parcialmente ignorante? Não necessariamente. Pois essa escolha coloca outros desafios diante do escritor, solicitando tratamentos diferentes do objeto narrado. No caso de Pron e seu provável desejo de inserir-se numa arena pública de memória, a escolha por se produzir durante a escritura é inevitável, afinal seu movimento depende da apropriação de eventos que viveu apenas lateralmente.

Os que herdaram a ditadura,

[em] vez de construírem, como filhos, uma versão pessoal permeada e mediada do período imediatamente anterior 
que não tinham vivido, propuseram um relato compacto e global dessa história contemporânea à juventude ou maturidade de seus pais, para que os equívocos, as fantasias ou as limitações ideológicas das quais eles foram culpados não se repetissem no futuro. Não há vazio nesses discursos, não há fragmentação. Os filhos criticaram as opções dos pais e se referiram a esse passado político para superá-lo, não porque se sentissem diretamente afetados, mas porque isso fazia parte de uma dimensão pública (SARLO, 2017, p. 104).

Portanto existem diálogos procedimentais nessa literatura dos filhos, expressão que foi usada inicialmente por Alejandro Zambra, em capítulo do seu livro Formas de voltar para casa (2014), e que hoje é utilizada enquanto caracterização de escritos daqueles que não viveram, mas herdaram histórias, traumas, marcas das ditaduras latino-americanas. O percurso escolhido por Pron é muito parecido, por exemplo, com os de Zambra, na obra citada, e Julián Fuks, em A resistência (2015): neles também há narradores escrutinando as próprias infâncias (em períodos de guerra suja) num registro ensaístico e precário.

A literatura é inespecífica, mas existe uma especificidade no modo como esse conjunto de obras recupera as ditaduras. O exame da literatura dos filhos possivelmente aponta o surgimento de um evento discursivo: gerações posteriores apropriando-se de acontecimentos que não lhes atravessaram diretamente. O que pode ser contado quando se conta a partir desse lugar?

Produzir memória, investir sentidos no lugar de quem herda (ou de quem assume discursos), é um desafio ético e estético. Enquanto críticos, também escolhemos este lugar de quem não tem certezas a oferecer, aproximando-nos de maneira preliminar, tateando o objeto, percebendo suas extremidades, descidas, esconderijos e, sobretudo, possibilidades: encontrando, portanto, mais potências do que faltas.

\section{Referências}

COSTA, Julia Morena; SANTOS, Priscila Machado Barreto. La novela de los hijos: la memoria reivindicada em Fosmas de volver a casa, de Alejandro Zambra. In: ACOSTA, Juan Diego Ortiz; FLORES, Jaime Arturo Chavolla 
0 ENSAIO COMO PROCEDIMENTO DE LEITURA-ESCRITURA EM "0 ESPIRITO DOS MEUS PAIS CONTINUA A SUBIR NA CHUVA"

(coord.). Estudios filosóficos: filosofia y pensamiento latinoamericano. Guadalajara: Universidad de Guadalajara, 2016.

FUKS, Julián. A resistência. São Paulo: Cia das Letras, 2014.

GARRAMUÑO, Florencia. Frutos estranhos: sobre a inespecificidade na estética contemporânea. Trad. de Carlos Nougué. Rio de Janeiro: Rocco, 2014

JABLONKA, Ivan. O terceiro continente. Trad. Alexandre de Sá Avelar. ArtCultura, v. 19, n. 35, p. 9-17, jul.-dez, 2017.

LADDAGA, Reinaldo. Estética de laboratório: estratégias das artes do presente. Trad. Magda Lopes. São Paulo: Martins Fontes, 2013.

LUDMER, Josefina. Aqui América Latina. Trad. de Rômulo Monte Alto. Belo Horizonte: Editora UFMG, 2013.

LVOVICH, Daniel; BISQUERT, Jaquelina. La cambiante memoria de la dictadura: discursos públicos, movimientos sociales y legitimidad democrática. Las polvorines: Univ. Nacional de General Sarmiento; Buenos Aires: Biblioteca Nacional, 2008.

MILTON, Cynthia E. El arte desde el pasado fracturado. In: MILTON, Cynthia E (Org.). El arte desde el pasado fracturado peruano. Lima: Instituto de Estudios Peruanos, 2018.

PRON, Patricio. O espírito dos meus pais continua a subir na chuva. Trad. de Gustavo Pacheco. São Paulo: Todavia, 2018.

SAER, Juan José. O conceito de ficção. Revista FronteiraZ, São Paulo, no 8, 2012.

SARLO, Beatriz. Tempo passado: cultura da memória e guinada subjetiva. Trad. de Rosa Freire d'Aguiar. São Paulo: Companhia das Letras; Belo Horizonte: Editora UFMG, 2017.

STAROBINSKI, Jean. É possível definir o ensaio? Trad. Bruna Torlay. Remate de Males, v. 31, n. 1, p. 13-24, jan./dez, 2011.

STERN, Steve J. La verdad del artista: el dilema post-Auschwitz después de la era latinoamericana de las guerras sucias. In: MILTON, Cynthia E. (Org.). El arte desde el pasado fracturado peruano. Lima: Instituto de Estudios Peruanos, 2018.

TOLENTINO, Marcos. O 16 de setembro sob a ótica do DIPBA: Dirección de inteligencia de la policía de la provincia de Buenos Aires (1990-1996). 2012. $175 \mathrm{f}$. 
Dissertação (Mestrado em História) - Instituto de Filosofia e Ciências Humanas, Universidade Estadual de Campinas, Campinas, 2012.

VIDAL, Paloma. Una literatura ignorante: notas sobre uma novela. In: Clepsidra, n. 1, p. 114-121, 2014.

WHITE, Hayden. Trópicos do discurso: ensaios sobre a crítica da cultura. Trad. Alípio Correia de Franca Neto. São Paulo: Editora da Universidade de São Paulo, 1994.

ZAMBRA, Alejandro. Formas de voltar para casa. Trad. de José Geraldo Couto. São Paulo: Cosac Naify, 2014.

Recebido em 20 de novembro de 2020

Aceito em 15 de dezembro de 2020 